\title{
Effect of Plate Type and Working Length on a Synthetic Compressed Juxta-Articular Fracture Model
}

\author{
Guy Bird ${ }^{1} \quad$ Mark Glyde $^{1}$ Giselle Hosgood ${ }^{1} \quad$ Alex Hayes $^{2}$ Rob Day ${ }^{2}$ \\ ${ }^{1}$ College of Veterinary Medicine, Murdoch University, Perth, Australia \\ ${ }^{2}$ Department of Medical Engineering and Physics, Royal Perth \\ Hospital, Perth, Australia \\ Address for correspondence Guy Bird, BVSc, GradDipEd, MVetSurg, \\ College of Veterinary Medicine, Murdoch University, Perth 6150, \\ Australia (e-mail: guypbird@gmail.com).
}

VCOT Open 2020;3:e119-e128.

\begin{abstract}
Keywords

- biomechanics

- working length

- plate strain

Objective This investigation compared the biomechanical properties of a $2.0 \mathrm{~mm}$ locking compression notched head T-plate (NHTP) and $2.0 \mathrm{~mm}$ straight locking compression plate (LCP), in a compressed, short, juxta-articular fragment fracture model.

Methods Two different screw configurations were compared for the NHTP and LCP, modelling short (configuration 1) and long working length (configuration 2). Constructs were tested in compression, perpendicular and tension four-point bending and torsion. Plate surface strain was measured at 12 regions of interest using threedimensional digital image correlation. Stiffness and strain were compared.

Results The LCP was stiffer than the NHTP in all three planes of bending $(p<0.05)$. The NHTP was stiffer than the LCP in torsion $(p<0.05)$. The NHTP had greater strain than the LCP during compression bending and torsion $(p<0.0005)$. The short working length NHTP was stiffer in all three planes of bending and in torsion $(p<0.05)$ than the longer working length. The short working length LCP was stiffer in compression bending and in torsion $(p<0.05)$ than the longer working length. The long working length showed greater strain than the short working length at multiple regions of interest.

Conclusion In this experimental model of a compressed transverse fracture with a juxta-articular $9 \mathrm{~mm}$ fragment, a $2.0 \mathrm{~mm}$ LCP with two hybrid screws in the short fragment was stiffer than a $2.0 \mathrm{~mm}$ NHTP with three locking screws in the short fragment in three planes of bending but not torsion. Extending the working length of each construct reduced construct stiffness and increased plate strain.
\end{abstract}

\section{Introduction}

Fractures with a very short proximal or distal juxta-articular fragment create particular biomechanical challenges, complicating implant selection and placement. In veterinary orthopaedics, distal radial fractures in toy and miniature breeds are a common example of this, with the majority of these fractures reported to involve the distal third of the radius, resulting in a very short distal fragment. ${ }^{1,2}$ Plate

received

July 27,2020

accepted

August 10, 2020
DOI https://doi.org/

10.1055/s-0040-1716722. ISSN 2625-2325. fixation has been reported to have good overall success in these cases. $^{3}$

A recent clinical report described use of either a $2.0 \mathrm{~mm}$ notched head locking compression plate T-plate (NHTP) (LCP, Synthes $\mathrm{GmbH}$, Oberdorf, Switzerland) or a $2.0 \mathrm{~mm}$ straight locking compression plate (LCP) (Synthes GmbH, Oberdorf, Switzerland) for distal antebrachial fractures in toy and miniature breed dogs weighing less than $6 \mathrm{~kg}$. ${ }^{1}$ Differences in design include differing plate geometry and dimensions,
License terms

Stuttgart · New York

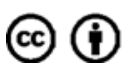


the number, position and type of screws that can be placed in a very short juxta-articular fragment. Given the design differences between the NHTP and equivalent-length straight LCP, it is expected they will have different biomechanical properties. There is no information on the comparable biomechanical performance of these two plates.

The $2 \mathrm{~mm}$ NHTP allows placement of locking screws in three stacked holes in a triangular configuration within the plate head. These three screws can be placed in a $9 \mathrm{~mm}$ long bone fragment. The $2 \mathrm{~mm}$ LCP permits placement of one locking screw and one cortical screw in the equivalent length fragment. Of the 20 cases reported by Gibert and colleagues, ${ }^{1}$ 10 cases were stabilized with only two screws placed in the distal fragment. Two of those cases were stabilized with a straight LCP with only one locking screw and one cortical screw placed. Hybrid fixation was performed in all dogs in one or both fragments. Hybrid fixation is a term to describe the combination of both locking and cortical screws within a single plate construct. ${ }^{4,5}$

Plate working length is one of the factors that affects construct stability. ${ }^{6-11}$ Working length is affected by size of the fracture gap, plate stand-off distance, distance between the innermost screws and load direction. The effect of working length on construct stability and plate strain/stress is still the subject of some controversy. ${ }^{11-14}$ A finite element analysis study demonstrated that a longer working length increased plate stress in a $6 \mathrm{~mm}$ fracture gap model, though paradoxically reduced plate stress in a $1 \mathrm{~mm}$ fracture gap model, during axial compression producing tension bending. ${ }^{6}$ Much of the information on the effect of working length on plate strain/stress is based on fracture gap models, ${ }^{6-8,15,16}$ with no information from compressed fracture models.

The first objective of this study was to compare the biomechanical properties of a $2.0 \mathrm{~mm}$ NHTP construct to a $2.0 \mathrm{~mm}$ straight LCP construct, applied to a synthetic compressed transverse fracture model, with a very short $9 \mathrm{~mm}$ fragment, using screw configurations that simulated clinical application. ${ }^{1}$ We hypothesized that the NHTP construct would be less stiff and have greater plate strain in bending; however, it would be stiffer and have less strain in torsion testing than the LCP construct.

The second objective was to compare the biomechanical properties of a second screw configuration that created a longer working length than the original screw configuration. We hypothesized that for each plate type, the screw configuration with the longer working length would create a construct that was less stiff and have greater plate strain in bending and torsion testing, compared with the original screw configuration with the shorter working length.

\section{Materials and Methods}

A synthetic, compressed, transverse fracture model was created using two Delrin (Delrin Acetal Polymer: Polytech Plastics Australasia, Jandakot, WA, Australia) tubes $100 \mathrm{~mm}$ in length, with a $12.5 \mathrm{~mm}$ outer diameter and a $7.4 \mathrm{~mm}$ inner diameter. The distal fragment modelled was $9 \mathrm{~mm}$ in length, which is within the reported range in a previous clinical series of distal radial fractures in dogs $<6 \mathrm{~kg}{ }^{1}$

The dimensions of the shaft of the NHTP are less than the LCP. The shaft of the NHTP has a width of $5 \mathrm{~mm}$ and thickness of $1.3 \mathrm{~mm}$, whereas the LCP has a width of $5.5 \mathrm{~mm}$ and thickness of $1.5 \mathrm{~mm} .^{17}$ The length of the $2 \mathrm{~mm}$ NHTP is comparable to the 8 -hole $2 \mathrm{~mm} \mathrm{LCP}, 54 \mathrm{~mm}$ and $55 \mathrm{~mm}$ respectively. The NHTP allows compression of a fracture from any of the shaft combination holes, all directing compression towards the head of the plate. The LCP allows compression from any of the combination holes; however, each plate half compresses towards the middle of the plate. ${ }^{17}$

\section{Configuration 1}

The NHTP and LCP were each applied as compression plates with no stand-off distance using bicortical screws positioned as end of fragment screws. ${ }^{18}$ The insertional torque applied to each screw was standardized using a $0.4 \mathrm{Nm}$ torque limiter (Torque Limiter, $0.4 \mathrm{Nm}$, with AO/ASIF Quick Coupling: Synthes $\mathrm{GmbH}$ ), as recommended for $2.0 \mathrm{~mm}$ screws. ${ }^{17}$ For all constructs, the method of implant placement was performed following Arbeitsgemeinschaft für Osteosynthesefragen (AO Foundation, Davos, Switzerland) recommendations. ${ }^{19}$

For the NHTP, three locking screws (Self-tapping Locking Screw Star Drive, Synthes $\mathrm{GmbH}$ ) were placed in the plate head in the short fragment. The short fragment was arbitrarily defined as the distal fragment. The fracture was compressed with a single cortical screw (Self-tapping Cortex Screw Star Drive: Synthes GmbH), placed as a compression screw, in the shaft hole immediately proximal to the fracture, plate hole six. Plate holes were numbered sequentially from proximal to distal in both plates. Two additional locking screws (Self-tapping Locking Screw Star Drive, Synthes $\mathrm{GmbH}$ ) were subsequently placed in the proximal segment in plate holes one and five (-Fig. 1A).

For the LCP, a locking screw (Self-tapping Locking Screw Star Drive, Synthes $\mathrm{GmbH}$, Oberdorf, Switzerland) was placed immediately proximal to the fracture in hole six followed by a single cortical screw (Self-tapping Cortex Screw Star Drive: Synthes $\mathrm{GmbH}$ ) placed as a compression screw in plate hole seven in the distal fragment. Further locked screws were placed in holes one, five and eight achieving three locking screws in the proximal fragment and one cortical screw and one locking screw in the distal fragment (-Fig. 1A).

\section{Configuration 2: Longer Working Length}

The longer working length constructs were created by leaving screws out immediately adjacent to the fracture in the proximal fragment. For both plates, two locking screws (Selftapping Locking Screw Star Drive, Synthes $\mathrm{GmbH}$ ) were placed in the first and second most proximal shaft holes. A compression cortical screw was placed in the third most proximal shaft hole in the NHTP. A third locking screw was placed in the third most proximal shaft hole in the LCP (-Fig. 1B). Screw placement in the short distal fragment was identical to screw configuration 1 . As with screw configuration 1, both plates were applied in compression, using 


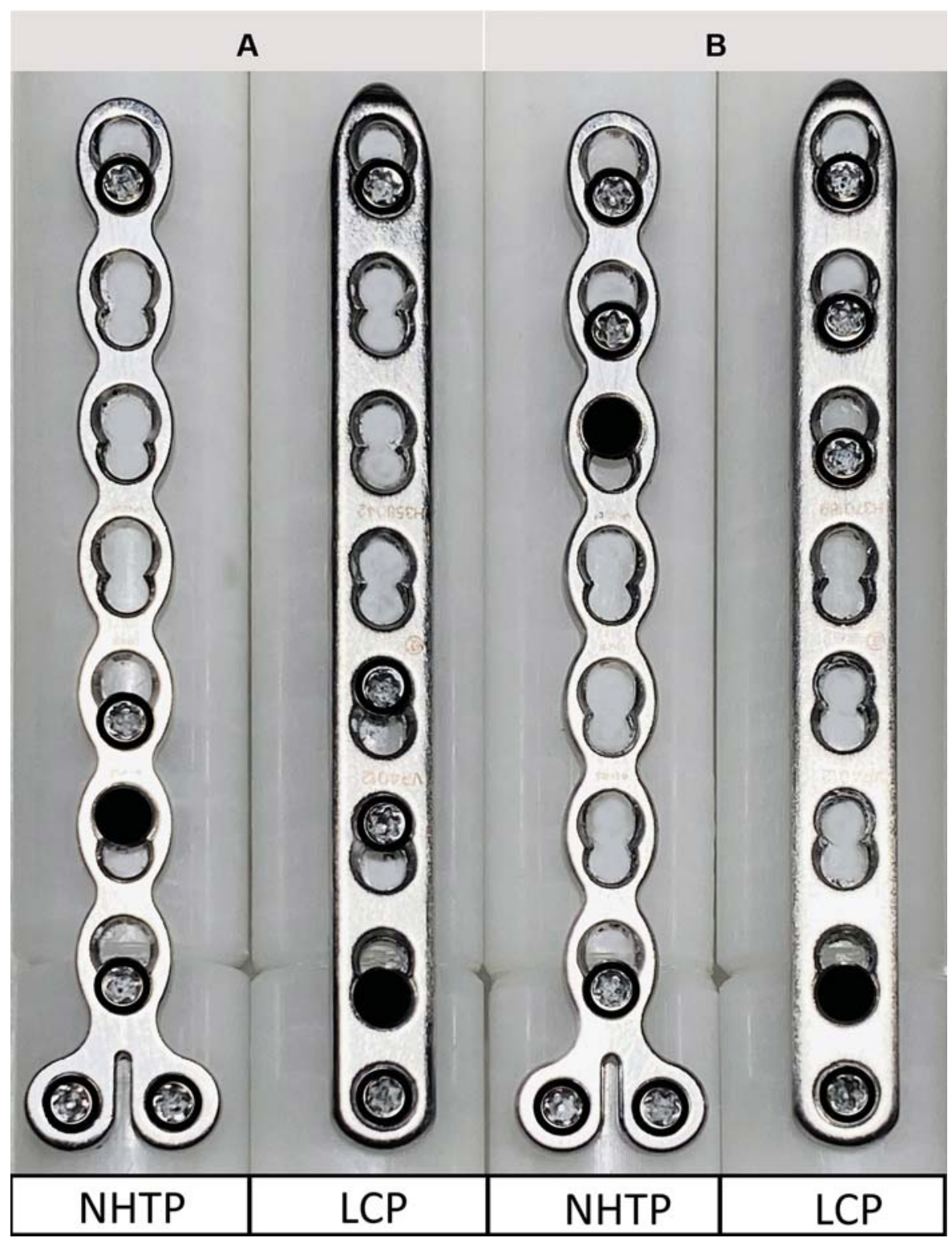

Fig. 1 (A) Configuration 1 constructs (short working length) for the notched head T-plate (NHTP) and straight locking compression plate (LCP). The hollow black circle indicates a locking screw. The solid black circle indicates a cortical screw in compression. (B) Configuration 2 (long working length) constructs.

bicortical screws with no plate stand-off distance. The sequence and method of screw placement followed AO (AO Foundation) recommendations. ${ }^{19}$

A sample size of seven replicates of each plate was used, sufficient to detect an effect size as small as 1.7 which is smaller than expected based on previous work using Delrin models (power $=0.8, \alpha=0.05$, variance $=10 \%)^{7}$

Non-destructive four-point quasi-static bending was conducted on a material testing machine (Instron 5848 MicroTester, Norwood, Massachusetts, United States) with a $100 \mathrm{~N}$ load cell, applying a constant bending moment of $0.6 \mathrm{Nm}$. The support rollers had a $200 \mathrm{~mm}$ gap and the load rollers had a $140 \mathrm{~mm}$ gap (-Fig. 2). Each construct was pre-loaded $(0.4 \mathrm{~N})$, then ramp loaded for three cycles under displacement control at $10 \mathrm{~mm} / \mathrm{min}$ to a force of $40 \mathrm{~N}$, to produce a peak bending moment of $0.6 \mathrm{Nm}$ in all tested planes. This bending moment was within the elastic limit of the constructs.
Each construct was sequentially tested in four-point bending about three different planes. Testing was first performed simulating compression bending, with load applied parallel to the screw axis along the compression surface of the construct ( $\mathbf{- F i g}$. 2A). The construct was then rotated 90 degrees and testing repeated, simulating perpendicular bending, with load applied perpendicular to the screw axis (-Fig. 2B). The construct was again sequentially rotated 90 degrees and testing repeated, to simulate tension bending, with load applied parallel to the screw axis ( $\mathbf{- F i g . ~ 2 C ) . ~}$

For testing in non-destructive torsion, the proximal end of the construct was restrained in a custom-made jig allowing free rotation. Axial load was applied to a jig screw using a material testing machine (Instron 5567: Instron, Canton, Massachusetts, United States) to create torque, resulting in a rotational displacement of $\sim 5.6$ degrees/s, to produce a peak vertical displacement of $5 \mathrm{~mm}$ (11.3 degrees torsion reached). 


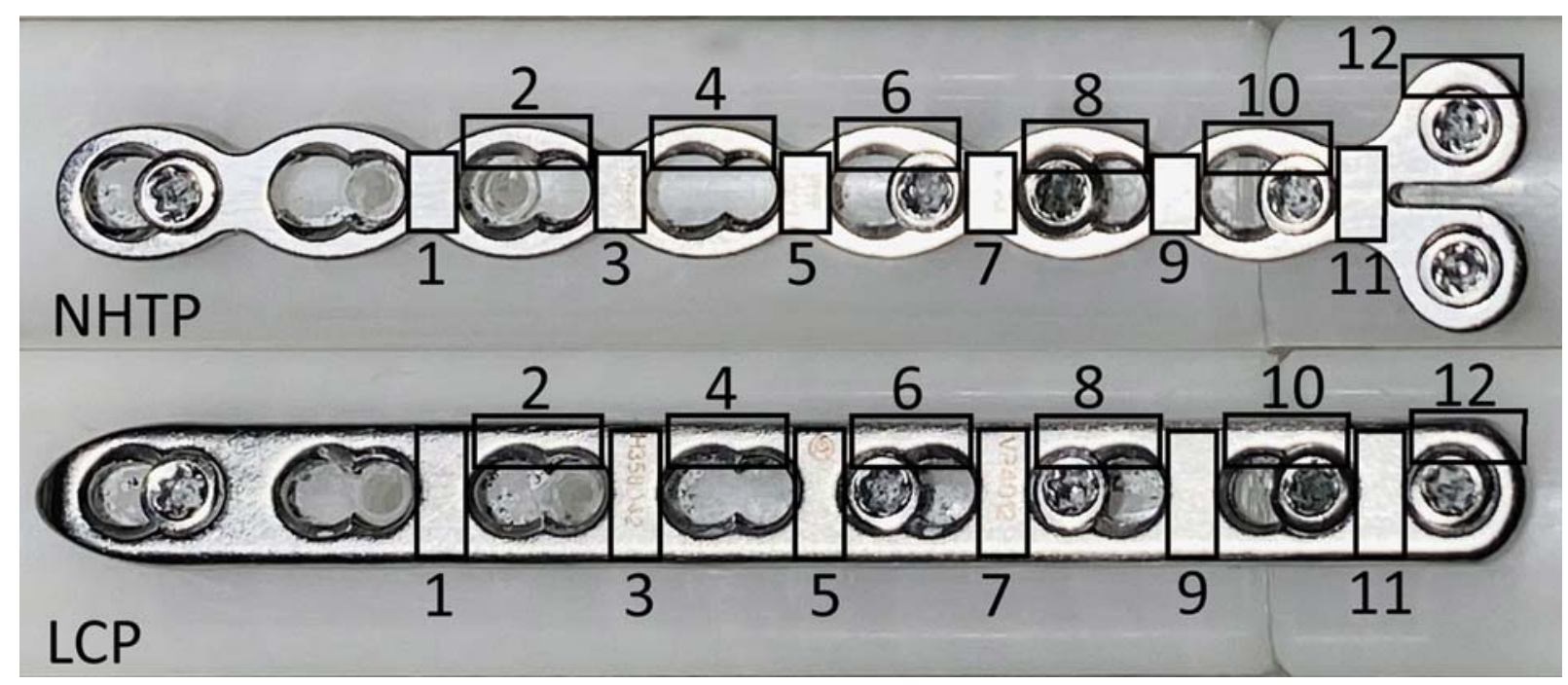

Fig. 3 Region of interest from where strain was measured for both plate types using three-dimensional digital image correlation. LCP, locking compression plate; NHTP, notched head T-plate.

\section{Measurement of Stiffness}

All testing load and actuator displacement measurements were recorded. Bending and torsional stiffness was determined from the slope of the linear elastic portion of the load displacement curve.

\section{Measurement of Strain}

Three-dimensional digital image correlation was used to measure plate surface strain during compression bending and torsion testing only. ${ }^{20-23}$ Each construct was sprayed with a speckle pattern (uniform base white followed by a black speckle) prior to testing. ${ }^{20}$ The high definition recordings were captured with VicSnap software (VicSnap, Correlated Solutions, North Carolina, United States). ${ }^{20}$ Strain was measured for 12 regions of interest (ROI) along the plate surface using Vic-3D software (VIC-3D, Correlated Solutions, North Carolina, United States) (-Fig. 3). ${ }^{20}$ The ROI were numbered sequentially, representative of analogous regions for both plates. The regions along the axial solid plate section were marked by odd numbers and the abaxial partial plate

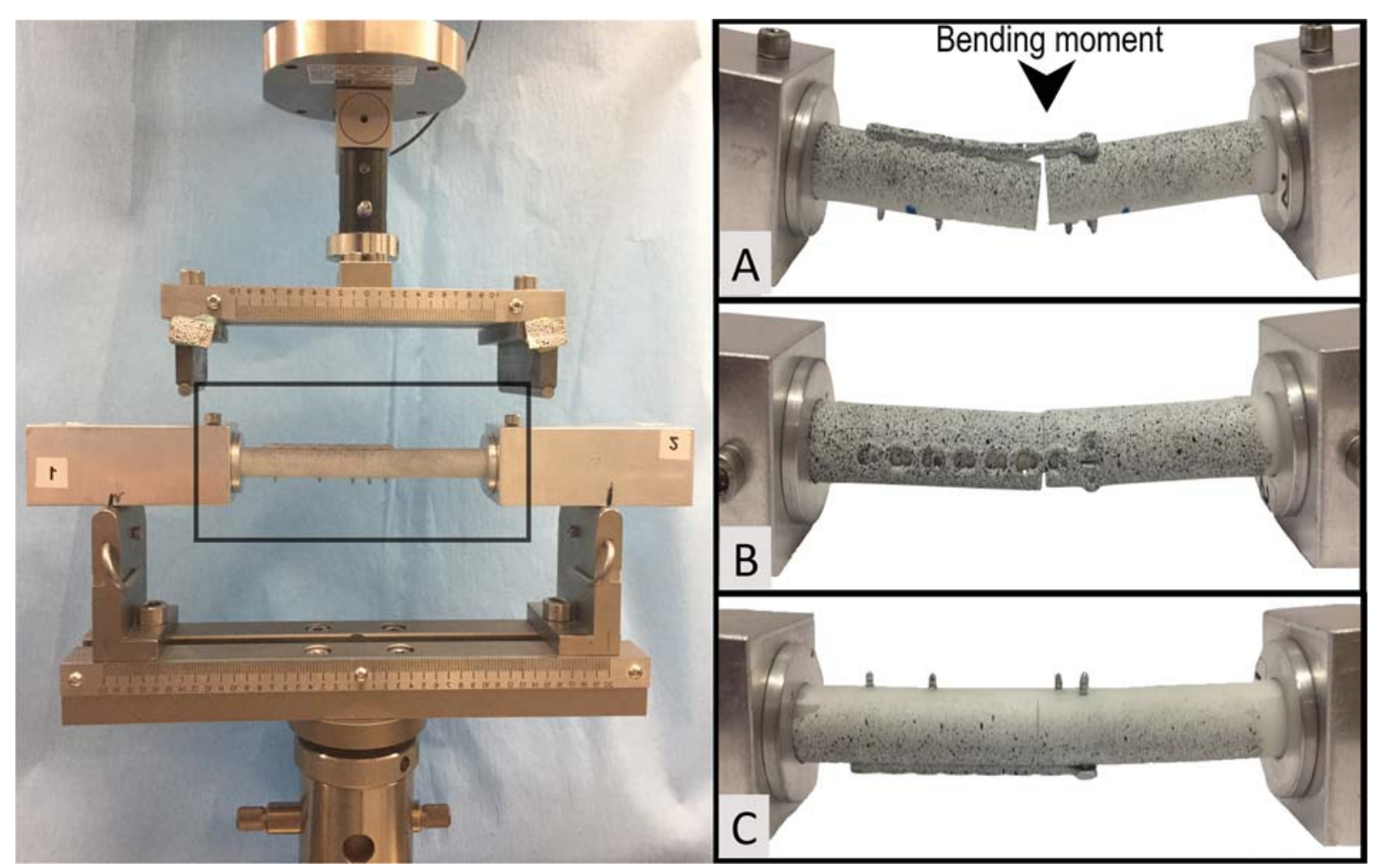

Fig. 2 Four-point bending was conducted on a material testing machine, applying a constant bending moment along the constructs about three different planes. (A) Compression bending. (B) Perpendicular bending. (C) Tension bending. 
sections, by even numbers. The mean von Mises strain was calculated from the linear line of best fit of the strain load graph from the third cycle, for each sample tested.

\section{Statistical Analysis}

The stiffness for each four-point bending and torsion test was the response of interest and confirmed to be normally distributed using the Shapiro-Wilk test and visual inspection of Q-Q plots. The stiffness was summarized as mean (95\% confidence interval, CI). The stiffness in each plane of bending for screw configuration 1 was compared between plate types using a $t$-test. The stiffness in each plane of bending was compared between screw configurations within each plate type using $t$-tests. Equality of variances was tested and either a pooled or Satterthwaite test of significance was used based on equality/non-equality variances, respectively, to avoid type 1 error. Significance was determined at $p \leq 0.05$.

The strain was verified as normally distributed using the Shapiro-Wilk test and visual inspection of Q-Q plots, and summarized as mean $(95 \% \mathrm{CI})$. The strain for screw configuration 1 was compared between plate types using a two-way analysis of variance including the main effects of plate type and ROI, and their interaction. When there was significant interaction ( $p \leq 0.05$ ), selected post-hoc, pairwise comparisons were made between plate types at each region against a Bonferroni-adjusted $p \leq 0.005$. The strain for configuration 1 and 2 was compared within each plate type using a twoway analysis of variance including the main effects of screw configuration and ROI, and their interaction. When there was significant interaction ( $p \leq 0.05)$, selected post-hoc pairwise comparisons were made between screw configuration for each ROI, within each plate type against a Bonferroni-adjusted $p \leq 0.005$. SAS v9.4 (SAS Institute, Cary, North Carolina, United States) was used for analysis.

\section{Results}

\section{Comparison of Plate Type for Screw Configuration 1}

The LCP was significantly stiffer than the NHTP in all three planes of bending ( $p \leq 0.05$, - Table 1 ). The NHTP was significantly stiffer than the LCP in torsion $(p \leq 0.05$, -Table 1).

Table 1 Mean (95\% confidence interval) stiffness in four-point compression, perpendicular and tension bending $(\mathrm{N} / \mathrm{mm})$ and torsion ( $\mathrm{Nm} /$ degree) with comparison between the NHTP and LCP screw configuration 1

\begin{tabular}{|l|l|l|l|l|}
\hline Plate & $\begin{array}{l}\text { Compression } \\
\text { bending }\end{array}$ & $\begin{array}{l}\text { Perpendicular } \\
\text { bending }\end{array}$ & $\begin{array}{l}\text { Tension } \\
\text { bending }\end{array}$ & Torsion \\
\hline NHTP & $\begin{array}{l}36.0 \\
(34.0-38.0)\end{array}$ & $\begin{array}{l}63.7 \\
(57.5-69.8)\end{array}$ & $\begin{array}{l}50.17 \\
(47.7-52.6)\end{array}$ & $\begin{array}{l}0.8 \\
(0.75-0.85)\end{array}$ \\
\hline LCP & 48.33 & 66.8 & 83.7 & 0.68 \\
& $(47.5-49.2)$ & $(65.0-68.5)$ & $(79.7-87.6)$ & $(0.65-0.71)$ \\
\hline$p$-Value & $\leq 0.0001$ & 0.0128 & $<0.0001$ & 0.0026 \\
\hline
\end{tabular}

Abbreviations: LCP, locking compression plate; NHTP, notched head T-plate.

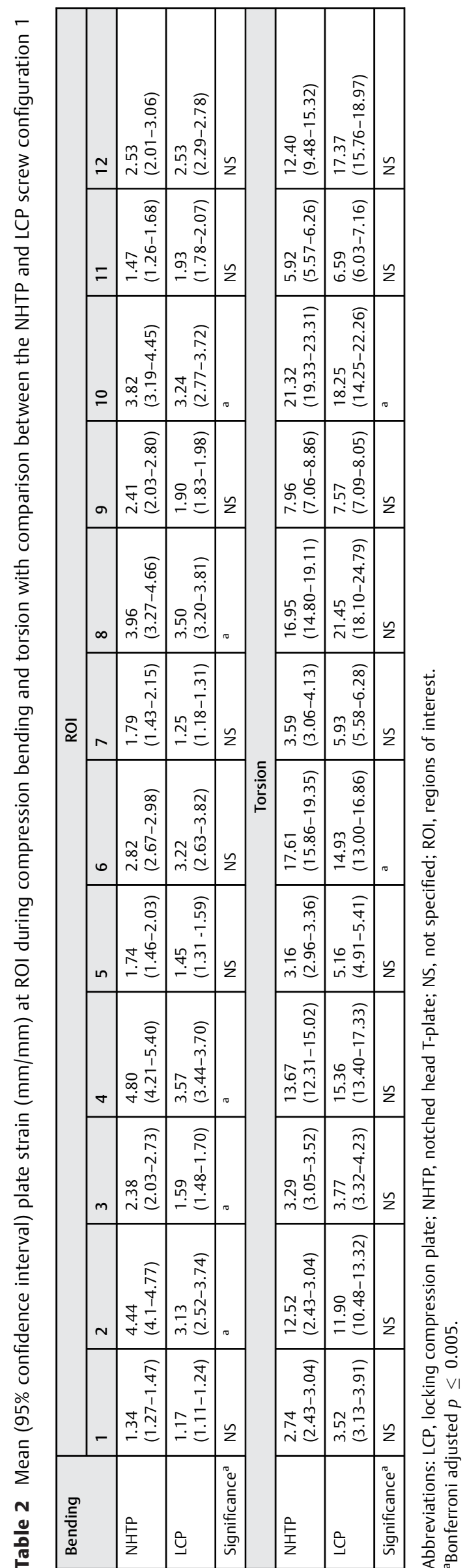


Table 3 Mean (95\% confidence interval) stiffness in four-point compression, perpendicular and tension bending (N/mm) and torsion (Nm/degree) of NHTP and LCP with comparison between screw configuration 1 and 2 for each plate type

\begin{tabular}{|l|l|l|l|l|}
\hline NHTP & Compression bending & Perpendicular bending & Tension bending & Torsion \\
\hline Configuration 1 (short working length) & 36.0 & 63.7 & 50.17 & 0.8 \\
& $(34.0-38.0)$ & $(57.5-69.8)$ & $(47.7-52.6)$ & $(0.75-0.85)$ \\
\hline Configuration 2 (long working length) & 16.47 & 53.24 & 39.4 & 0.63 \\
& $(14.9-17.9)$ & $(49.8-56.6)$ & $(38.2-40.6)$ & $(0.60-0.67)$ \\
\hline$p$-Value & $\leq 0.0001$ & $\leq 0.0001$ & $\leq 0.0001$ & 0.0003 \\
\hline LCP & Compression bending & Perpendicular bending & Tension bending & Torsion \\
\hline Configuration 1 (short working length) & 48.33 & 66.8 & 83.7 & 0.68 \\
& $(47.5-49.2)$ & $(65.0-68.5)$ & $(79.7-87.6)$ & $(0.65-0.71)$ \\
\hline Configuration 2 (long working length) & 26.99 & 70.16 & 77.69 & 0.53 \\
& $(25.9-28.0)$ & $(67.7-72.6)$ & $(73.0-82.3)$ & $(0.51-0.54)$ \\
\hline$p$-Value & $\leq 0.0001$ & 0.0640 & 0.1 & $\leq 0.0001$ \\
\hline
\end{tabular}

Abbreviations: LCP, locking compression plate; NHTP, notched head T-plate.

The NHTP had significantly greater strain than the LCP during compression bending at five of twelve ROI $(p \leq 0.005$, -Table 2), with no difference at the remaining regions.

The NHTP had significantly greater strain than the LCP during torsion testing at two of twelve ROI ( $p \leq 0.005$, - Table 2), with no difference at the remaining regions.

\section{Comparison of Screw Configuration 1 and 2: Notched Head T-plate}

Configuration 1 was significantly stiffer in all three planes of bending and in torsion ( $p \leq 0.05$, - Table 3 ).

Configuration 2 had significantly greater strain than configuration 1 during compression bending at all ROI $(p<0.005)$, except one region where there was no difference ( - Table 4 ).

Configuration 2 had significantly greater strain than configuration 1 in torsion at five ROI $(p<0.005)$, with no difference at the remaining seven regions ( - Table $\mathbf{5}$ ).

\section{Comparison of Screw Configuration 1 and 2: Straight LCP}

Configuration 1 was significantly stiffer in compression bending and in torsion ( $p \leq 0.05$, - Table 3 ), with no difference in perpendicular, and tension bending.

Configuration 2 had significantly greater strain than configuration 1 during compression bending at six ROI $(p<0.005)$, with no difference at the remaining six regions (-Table 4).

Configuration 2 had significantly greater strain than configuration 1 during torsion at four ROI $(p<0.005)$, with no difference at the remaining eight regions ( - Table 5 ).

\section{Discussion}

The results of this study confirmed our hypothesis that the NHTP construct would be less stiff than the LCP construct in bending. Our hypothesis that the NHTP would be stiffer in torsion was also confirmed. The greater stiffness in bending of the LCP plate was reflected in the plate strain with the LCP having lower strain than the NHTP. As hypothesized, the
NHTP had significantly greater strain in bending than the LCP. Our hypothesis that the NHTP would have lower plate strain than the LCP under torsional loading was not supported. Despite the NHTP having greater stiffness under torsional load than the LCP, the NHTP had higher plate strain than the LCP.

The placement of three locking screw in the short fragment in the NHTP did not overcome the presumed lower stiffness of the smaller shaft of that plate, compared with two axially positioned screws in the LCP with larger shaft dimensions. Factors that can influence the bending resistance of a plate construct under identical load conditions are the presence of a fracture gap, the modulus of elasticity of the plate material, the cross-sectional dimensions of the plate, the plate stand-off distance, the number of screws per fracture fragment, the working leverage of the screws in each fragment created by the distance between the end of fragment screws and the working length. ${ }^{6,13,18}$ Cross-sectional plate dimension is one of the key determinants of the resistance of a plate to bending loads, which is calculated as Area Moment of Inertia (AMI), and torsion loads, calculated as Polar Moment of Inertia (PMI). In our model, fracture compression was observed to be maintained in tension and perpendicular bending though not in compression bending or in torsion. Both the plates are 316L stainless steel and were applied with no stand-off from the bone and with identical working lengths. So, the relevant factors of influence in this model are the plate design/AMI and PMI, the number of screws per fracture fragment and the working leverage of the screws. The NHTP is a different shape with different dimension to the LCP. The LCP has a larger AMI and PMI than the NHTP and so would be expected to have greater resistance to bending, eccentric axial loading and torsion. We were particularly interested in the effect on construct stability of being able to place three locking screws in the head section of the NHTP in a very short juxta-articular segment compared with one locking screw and one cortical screw in the LCP and whether this would overcome the effect of different plate dimensions. 
Stoffel and colleagues ${ }^{6}$ showed that for the same working length, three screws per fracture fragment provided significantly increased resistance to eccentric axial compression when compared with two screws per fragment in a fracture gap model stabilized with $4.5 \mathrm{~mm}$ titanium LCP. Conversely, Pearson and colleagues ${ }^{7}$ using $3.5 \mathrm{~mm}$ straight LCP in a synthetic fracture gap model showed that for the same plate working length, three screws per fracture fragment did not significantly increase construct stiffness in tension bending compared with two screws; however, they did significantly increase axial stiffness and perpendicular bending stiffness. In our study, the three screws in the head of NTHP plate in the short fragment have the same axial working leverage as the two screws in the LCP distal fragment (-Fig. 1A and B). Working leverage is the distance between the inner and outermost screws of a fracture fragment. ${ }^{18}$ This may have contributed to the apparent lack of benefit of three screws compared with two screws in resisting bending. This was not the case for torsional load resistance.

The increased torsional resistance of the NHTP over the LCP can likely be attributed to the increased number of screws in the distal fragment and the abaxial screw position, creating a longer perpendicular leverage arm than the axially positioned LCP screws. The longer perpendicular working leverage likely mitigated the reduced PMI of the NHTP plate due to the smaller shaft cross-sectional area than the LCP plate. This finding was supported by Stoffel and colleagues, ${ }^{6}$ who found that stiffness under torsional load in a synthetic fracture gap bone model, stabilized with a standard LCP, increased significantly with more screws (up to four) per fragment. Similarly, in a study by Freeman and colleagues, ${ }^{24}$ torsional stiffness of hybrid constructs was most affected by the number of screws, where mean stiffness increased at least 33\% with four screws in each fracture fragment versus three per fragment.

Our study cannot discern the effect of screw type on increased torsional resistance of the NHTP, since our screw selection for each plate type was fixed. Previous studies testing a variety of different locking devices have suggested locking constructs have advantages over unlocked screws and plates. ${ }^{25-27}$ Freeman and colleagues $^{24}$ showed that replacement of three unlocked screws with locked screws significantly increased the torsional stiffness of the construct by $24 \%$. This finding was supported by Gordon and colleagues, ${ }^{26}$ who investigated the effect of combinations of locking and cortical screws on the torsional properties of locking-plate constructs. They found that the LCP construct was significantly stiffer in torsion than the non-LCP construct, with a mean $17 \%$ increase in torsional resistance after addition of a locking screw to a non-locking construct. ${ }^{26}$

Under identical load, plate strain was greater along the NHTP than the LCP at five ROI in compression bending. This is not surprising, biomechanical studies have shown a stiffer construct will have reduced plate strain. ${ }^{15,20,28,29}$ The plate strain was greater along the NHTP than the LCP at two ROI when loaded in torsion. This was surprising given the NHTP was stiffer during torsional loading than the LCP. The reason for this is not clear; however, it may reflect an interaction 


\begin{tabular}{|c|c|c|c|c|c|c|}
\hline & 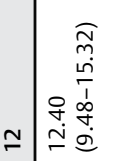 & 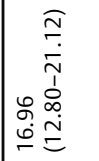 & 1. & 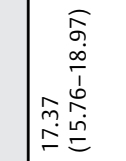 & 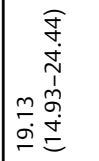 & $\tilde{z}$ \\
\hline & 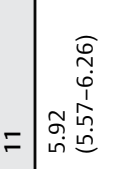 & \begin{tabular}{rl} 
& \multicolumn{2}{c}{} \\
0 \\
0 \\
0 \\
0 \\
0 \\
0 \\
0 & 0 \\
0 & 0
\end{tabular} & $\tilde{z}$ & 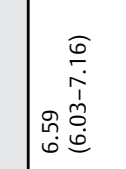 & 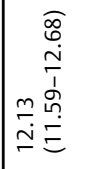 & $\tilde{z}$ \\
\hline & 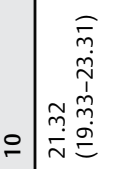 & 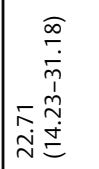 & $\Sigma \bar{z}$ & 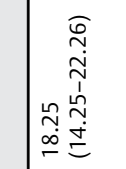 & 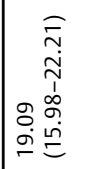 & $\tilde{z}$ \\
\hline & 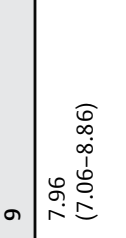 & 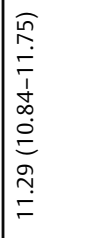 & $\tilde{z}$ & 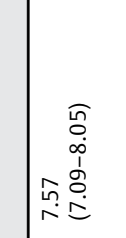 & 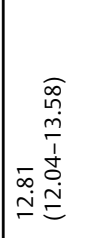 & $\tilde{z}$ \\
\hline & 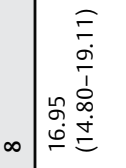 & 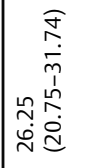 & . & 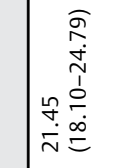 & 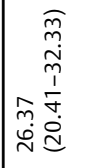 & $\tilde{z}$ \\
\hline$\overline{\bar{q}}$ & 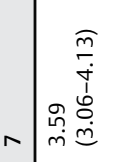 & 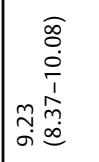 & $\tilde{z}$ & 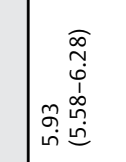 & 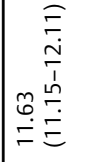 &. \\
\hline & 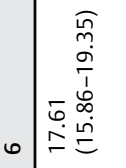 & 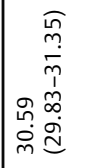 & 10 & 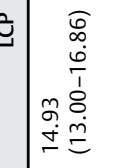 & 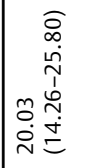 & $\tilde{z}$ \\
\hline & n & 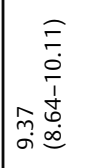 & . & 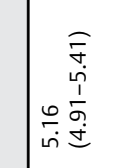 & 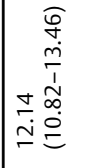 & . \\
\hline & 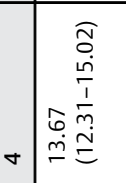 & 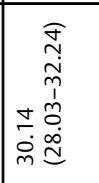 & . & 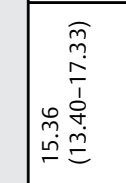 & 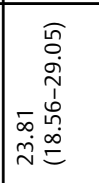 &. \\
\hline & 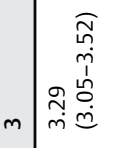 & 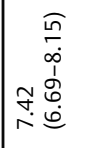 & $\tilde{z}$ & 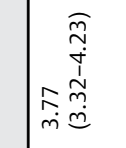 & 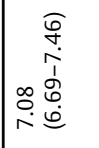 & $\tilde{z}$ \\
\hline & 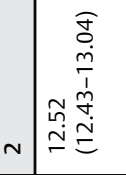 & 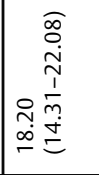 & $\tilde{z}$ & 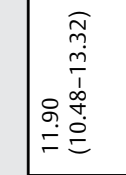 & 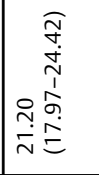 & . \\
\hline & 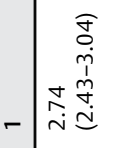 & 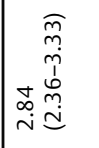 & $\tilde{z}$ & 商 & 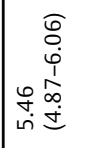 & $\tilde{z}$ \\
\hline 产 & 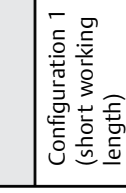 & 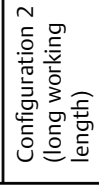 & 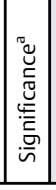 & 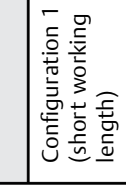 & 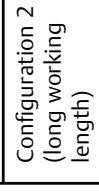 & 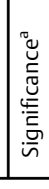 \\
\hline
\end{tabular}

between the reduced PMI of the smaller cross-sectional area of the NHTP and the increased perpendicular screw leverage arm of the abaxial positioned head screws.

Our second hypothesis, that for both plate types, the long working length constructs would be less stiff and have higher plate strain than the short working length constructs in bending and in torsion was confirmed with the exception of perpendicular and tension bending for the LCP. The working length was altered in this study, by maintaining the same number and type of screws in each fracture fragment and only changing the screw location in the proximal fragment. This avoided confounding the effect of changing the working length with a concurrent change in number of screws.

In a compressed, reduced fracture model, load-sharing is maintained under tension and perpendicular bending; however, load-sharing is not maintained under compression bending and under torsional loading. During both compression bending and torsional loading, loss of contact or gapping of the Delrin bone model occurs and consequently the working length becomes the distance between the innermost screws closest to the fracture line and load is resisted by the implant alone. ${ }^{30}$ Increasing the working length by leaving three screw holes vacant adjacent to the fracture line in the proximal fragment reduced mean compression bending stiffness for the NHTP $(36-16.5 \mathrm{~N} / \mathrm{mm})$ and LCP $(48.3-27 \mathrm{~N} / \mathrm{mm})$, by $\sim 54$ and $44 \%$ respectively and mean torsional stiffness for the NHTP (0.8-0.63 Nm/degree) and LCP (0.68 to $0.52 \mathrm{Nm} /$ degree) by $\sim 21$ and $22 \%$ respectively. These findings are consistent with other studies that demonstrated greater construct stiffness with shorter working lengths. ${ }^{6-11,31}$

Plate strain was determined at twelve ROI using digital image correlation for both plate types under compression bending and torsion. At no ROI, mean plate strain was reduced by increasing working length under either load direction. This is not surprising, since both compression bending and torsion produce gapping of the fracture and loss of load-sharing which immediately transfers load resistance to the implants alone, resulting in reduced construct stiffness. Previous biomechanical studies have shown that plate strain is inversely related to construct stiffness. ${ }^{15,20,28,29,32,33}$

Despite these previous biomechanical studies, the relationship between plate strain and working length remains controversial in the literature. ${ }^{11,12,14,34}$ This controversy is generated from work using a non-compressed $1 \mathrm{~mm}$ fracture gap model where plate stress was calculated in an analytical fine element analysis model loaded under axial compression producing tension bending. ${ }^{6}$ In that modelling, increasing the working length paradoxically reduced plate strain that was explained by early interfragmentary contact across the transcortical gap creating load-sharing and thereby increased construct stiffness and decreased plate strain. While the authors acknowledged this confounding factor, we believe that these results have been misinterpreted in the literature. ${ }^{11,13}$ We believe the fracture conditions modelled by Stoffel and colleagues ${ }^{6}$ are unlikely to be realistic for a clinical situation. Eccentric axial loading producing only tension bending in a small gap, transverse fracture without concurrent torsional and compressive loads would be an 
unlikely clinical scenario. Simple transverse fractures are typically managed with compression to achieve absolute stability. Furthermore, the transcortical bone contact modelled in that study would produce high interfragmentary strain, initiating bone resorption at the fracture gap. ${ }^{35-38}$ The consequent gap widening, necessary to reduce interfragmentary strain to levels where fibrous tissue could begin to form, could be expected to prolong fracture healing and promote further plate deformation. In such a situation, successful healing could only occur if fracture biology in that case was powerful enough to produce a healing time that was within the fatigue life and capacity of the implant. ${ }^{39,40}$

\section{Conclusion}

In this experimental model of a compressed simple transverse fracture with a juxta-articular $9 \mathrm{~mm}$ distal fragment, a $2.0 \mathrm{~mm}$ LCP with two hybrid screws in the short fragment was significantly stiffer than a $2.0 \mathrm{~mm}$ NHTP with three locking screws in the short fragment in compression, tension and perpendicular bending but not torsion. Extending the working length of each construct by omitting locking screws adjacent to the fracture significantly reduced construct stiffness and increased plate strain.

\section{Authors' Contributions}

All the authors conceptualized and designed the study. G.B., M.G., G.S. acquired the data. G.B., M.G., R.D., A.H. acquired the data. G.B., M.G., G.H., R.D. revised the manuscript critically. All the authors interpreted the data.

\section{Conflict of Interest}

None declared.

Acknowledgments

The authors would like to thank DePuy Synthes for partial financial support for the implants used in this study.

\section{References}

1 Gibert S, Ragetly GR, Boudrieau RJ. Locking compression plate stabilization of 20 distal radial and ulnar fractures in toy and miniature breed dogs. Vet Comp Orthop Traumatol 2015;28(06): 441-447

2 De Arburn Parent R, Benamou J, Gatineau M, Clerfond P, Planté J. Open reduction and cranial bone plate fixation of fractures involving the distal aspect of the radius and ulna in miniatureand toy-breed dogs: 102 cases (2008-2015). J Am Vet Med Assoc 2017;250(12):1419-1426

3 Aikawa T, Miyazaki Y, Shimatsu T, Iizuka K, Nishimura M. Clinical outcomes and complications after open reduction and internal fixation utilizing conventional plates in 65 distal radial and ulnar fractures of miniature- and toy-breed dogs. Vet Comp Orthop Traumatol 2018;31(03):214-217

4 Gardner MJ, Griffith MH, Demetrakopoulos D, et al. Hybrid locked plating of osteoporotic fractures of the humerus. J Bone Joint Surg Am 2006;88(09):1962-1967

5 Scolaro J, Ahn J. Locked plating in practice: indications and current concepts. Univ Pennsylvania Orthop J 2011;21:18-22

6 Stoffel K, Dieter U, Stachowiak G, Gächter A, Kuster MS. Biomechanical testing of the LCP-how can stability in locked internal fixators be controlled? Injury 2003;34(02, Suppl 2):B11-B19
7 Pearson T, Glyde M, Hosgood G, Day R. The effect of intramedullary pin size and monocortical screw configuration on locking compression plate-rod constructs in an in vitro fracture gap model. Vet Comp Orthop Traumatol 2015;28(02):95-103

8 Hulse D, Hyman W, Nori M, Slater M. Reduction in plate strain by addition of an intramedullary pin. Vet Surg 1997;26(06):451-459

9 Ricci W, Tornetta P, Zheng Y, et al. Biomechanical investigation of plate working length on fatigue characteristics of locking Plate constructs in human cadaveric distal metaphyseal femoral fracture models. New Orleans, LA: 56th Annual Meeting of the Orthopaedic Research Society; 2007 (Poster No. 1754)

10 Lee CH, Shih KS, Hsu CC, Cho T. Simulation-based particle swarm optimization and mechanical validation of screw position and number for the fixation stability of a femoral locking compression plate. Med Eng Phys 2014;36(01):57-64

11 MacLeod AR, Serrancoli G, Fregly BJ, Toms AD, Gill HS. The effect of plate design, bridging span, and fracture healing on the performance of high tibial osteotomy plates: an experimental and finite element study. Bone Joint Res 2019;7(12):639-649

12 Smith WR, Ziran BH, Anglen JO, Stahel PF. Locking plates: tips and tricks. J Bone Joint Surg Am 2007;89(10):2298-2307

13 Gautier E, Sommer C. Guidelines for the clinical application of the LCP. Injury 2003;34(02, Suppl 2):B63-B76

14 Miller DL, Goswami T. A review of locking compression plate biomechanics and their advantages as internal fixators in fracture healing. Clin Biomech (Bristol, Avon) 2007;22(10):1049-1062

15 Kanchanomai C, Muanjan P, Phiphobmongkol V. Stiffness and endurance of a locking compression plate fixed on fractured femur. J Appl Biomech 2010;26(01):10-16

16 Chen G, Schmutz B, Wullschleger M, Pearcy MJ, Schuetz MA. Computational investigations of mechanical failures of internal plate fixation. Proc Inst Mech Eng H 2010;224(01):119-126

17 Veterinary Product Catalog Implants. Instruments, Sets. West Chester, PA: DePuy Synthes Vet. 2017

18 Wagner M, Frigg R. AO Manual of Fracture Management: Internal Fixators. Davos Platz, Switzerland: AO Publishing; 2006

19 Johnson AL, Vannini R, Houlton JE. AO Principles of Fracture Management in the Dog and Cat. Vol 148. Davos Platz: AO Publishing; 2005

20 Pearson T, Glyde MR, Day RE, Hosgood GL. The effect of intramedullary pin size and plate working length on plate strain in locking compression plate-rod constructs under axial load. Vet Comp Orthop Traumatol 2016;29(06):451-458

21 Sztefek P, Vanleene M, Olsson R, Collinson R, Pitsillides AA, Shefelbine $S$. Using digital image correlation to determine bone surface strains during loading and after adaptation of the mouse tibia. J Biomech 2010;43(04):599-605

22 Väänänen SP, Amin Yavari S, Weinans H, Zadpoor AA, Jurvelin JS, Isaksson $\mathrm{H}$. Repeatability of digital image correlation for measurement of surface strains in composite long bones. J Biomech 2013;46(11):1928-1932

23 Helgason B, Gilchrist S, Ariza O, et al. Development of a balanced experimental-computational approach to understanding the mechanics of proximal femur fractures. Med Eng Phys 2014;36(06): 793-799

24 Freeman AL, Tornetta P III, Schmidt A, Bechtold J, Ricci W, Fleming M. How much do locked screws add to the fixation of "hybrid" plate constructs in osteoporotic bone? J Orthop Trauma 2010;24 (03):163-169

25 Fulkerson E, Egol KA, Kubiak EN, Liporace F, Kummer FJ, Koval KJ. Fixation of diaphyseal fractures with a segmental defect: a biomechanical comparison of locked and conventional plating techniques. J Trauma 2006;60(04):830-835

26 Gordon S, Moens NMM, Runciman J, Monteith G. The effect of the combination of locking screws and non-locking screws on the torsional properties of a locking-plate construct. Vet Comp Orthop Traumatol 2010;23(01):7-13

27 Gardner MJ, Brophy RH, Campbell D, et al. The mechanical behavior of locking compression plates compared with dynamic 
compression plates in a cadaver radius model. J Orthop Trauma 2005;19(09):597-603

28 Matres-Lorenzo L, Diop A, Maurel N, Boucton MC, Bernard F, Bernardé A. Biomechanical comparison of locking compression plate and limited contact dynamic compression plate combined with an intramedullary rod in a canine femoral fracture-gap model. Vet Surg 2016;45(03):319-326

29 Bichot S, Gibson TWG, Moens NMM, Runciman RJ, Allen DG, Monteith GM. Effect of the length of the superficial plate on bending stiffness, bending strength and strain distribution in stacked 2.0-2.7 veterinary cuttable plate constructs. An in vitro study. Vet Comp Orthop Traumatol 2011;24(06):426-434

30 MacLeod AR, Pankaj P. Pre-operative planning for fracture fixation using locking plates: device configuration and other considerations. Injury 2018;49 June(Suppl 1):S12-S18

31 Vallefuoco R, Le Pommellet H, Savin A, et al. Complications of appendicular fracture repair in cats and small dogs using locking compression plates. Vet Comp Orthop Traumatol 2016;29(01):46-52

32 Knudson D. Fundamentals of Biomechanics. 2nd edition New York: Springer Science + Business Media; 2003

33 Chao P, Lewis DD, Kowaleski MP, Pozzi A. Biomechanical concepts applicable to minimally invasive fracture repair in small animals. Vet Clin North Am Small Anim Pract 2012;42(05):853-872, v
34 Strauss EJ, Schwarzkopf R, Kummer F, Egol KA. The current status of locked plating: the good, the bad, and the ugly.J Orthop Trauma 2008;22(07):479-486

35 Nourisa J, Baseri A, Sudak L, Rouhi G. The effects of bone screw configurations on the interfragmentary movement in a long bone fixed by a limited contact locking compression plate. J Biomed Sci Eng 2015;08(09):590-600

36 Märdian S, Schaser KD, Duda GN, Heyland M. Working length of locking plates determines interfragmentary movement in distal femur fractures under physiological loading. Clin Biomech (Bristol, Avon) 2015;30(04):391-396

37 Ramanauskaite K, Riškevičien V, Grigalevičiene B, Juodžente D. Factors that affect healing in cases of canine antebrachium fractures. Vet Zootech 2017;75(97):58-64

38 Schell H, Thompson MS, Bail HJ, et al. Mechanical induction of critically delayed bone healing in sheep: radiological and biomechanical results. J Biomech 2008;41(14):3066-3072

39 Ulstrup AK. Biomechanical concepts of fracture healing in weightbearing long bones. Acta Orthop Belg 2008;74(03):291-302

40 Welch JA, Boudrieau RJ, DeJardin LM, Spodnick GJ. The intraosseous blood supply of the canine radius: implications for healing of distal fractures in small dogs. Vet Surg 1997;26(01): 57-61 